\title{
Stem cell transplantation for ischemic cardiomyopathy: Hope or hype?
}

Vivek Rao, MD, PhD

See related article on page 1631.

From the Heart Transplant Program, Toronto General Hospital, University of Toronto, Toronto, Ontario, Canada.

Received for publication Aug 12, 2005; accepted for publication Aug 16, 2005.

Address for reprints: Vivek Rao, MD, PhD, 4N-464, 200 Elizabeth St, Toronto General Hospital, Toronto, Ontario M5G 2C4, Canada (E-mail: vivek.rao@uhn.on.ca).

J Thorac Cardiovasc Surg 2005;130:1492-3

$0022-5223 / \$ 30.00$

Copyright () 2005 by The American Association for Thoracic Surgery

doi:10.1016/j.jtcvs.2005.08.016
$\mathrm{U}$ ntil recently, the adult mammalian heart was considered a terminally differentiated organ incapable of regeneration. Remarkable observational data reported by Anversa and others challenged this dogma and postulated that under appropriate circumstances, the myocardium does indeed have a limited regenerative capacity secondary to a population of pluripotent stem cells. ${ }^{1,2}$ The last several years have seen a flurry of research activity into the promise of stem cell therapy for end-stage heart disease. The first clinical reports of feasibility further encouraged investigation into this exciting new field. ${ }^{3}$ As with most new areas of investigation, once the excitement surrounding the initial discovery wanes, the real science begins. $^{4}$

In this issue of the Journal, Patel and colleagues ${ }^{5}$ report preliminary data from a prospective randomized trial in patients subjected to hybrid surgical revascularization with or without autologous bone marrow-derived stem cell injections. The authors are to be congratulated for providing the readership with one of the first prospective surgical evaluations of this new therapy. The design of this trial was carefully considered and should be discussed in more detail.

All patients underwent percutaneous coronary interventions to all diseased territories apart from the left anterior descending coronary artery to avoid the confounding inflammatory effects of cardiopulmonary bypass. Patients were then subjected to a full sternotomy and an off-pump left internal thoracic artery to left anterior descending coronary artery anastomosis. In patients randomized to cell therapy, approximately $500 \mathrm{~mL}$ of bone marrow was harvested from the iliac crest. The authors claim that only a minimal number of puncture sites were required to obtain this volume and that a minimum aspirate of $250 \mathrm{~mL}$ was required to continue with the protocol. Apparently, all 10 patients randomized to cell therapy successfully yielded this minimum volume of marrow. The aspirate was then subjected to centrifugation and purification to yield a population of cells that were more than $70 \%$ positive for CD34, a marker of endothelial lineage. The purified cell suspension was then diluted in $30 \mathrm{~mL}$ of the patient's own plasma in preparation of epicardial injection. The authors do not report the median time required to prepare their cell concentrate but do admit to testing the limits of surgical patience (R. Kormos, personal communication). A specialized injection needle was used that lacked an end hole, enabling subepicardial injection with minimal leakage into the pericardial cavity. An important methodological detail involved the injection of cells only into viable or peri-infarct tissue and not directly into the center of obvious myocardial scar. Importantly, no attempt was made to introduce an intracoronary injection of cells. Also, the off-pump coronary artery bypass grafting (OPCAB)only group did not receive a placebo injection of plasma.

The primary end point of this study was the improvement in left ventricular ejection fraction, as measured with transthoracic echocardiography. Although admittedly a weak assessment of ventricular function that is highly variable and load dependent, the authors were able to demonstrate significant differences between groups at 1 month that persisted until the 6-month follow-up. The magnitude of the absolute difference in left ventricular ejection fraction is subtle at only $6 \%$ to $9 \%$. Interpreted another way, the OPCAB-only group demonstrated an improvement in left ventricular ejection fraction of only $6 \%$ to $7 \%$, whereas the OPCAB plus cell transplantation group exhibited a $12 \%$ to $16 \%$ improvement. Importantly, no ad- 
verse effects were observed that could be related to the injection of cells. This is in contrast to the earlier report by Menasche and associates ${ }^{3}$ that raised concern about the potential proarrhythmic effects of cell transplantation.

Again, as with any important study, the present report raises more questions than it answers. Most experts now agree that clinical cell transplantation can be performed with minimal morbidity, yet the efficacy and the mechanism of benefit remain unclear. An earlier award-winning study by $\mathrm{Chu}$ and coworkers ${ }^{6}$ from McGill demonstrated that needle puncture of the myocardium was equally as efficacious as transmyocardial laser revascularization. Is the mechanism of benefit in this study solely a result of the multiple needle punctures, or is there actual engraftment of cells with transformation into angiogenic or myogenic tissue? Is it important to purify the marrow aspirate to obtain enriched $\mathrm{CD} 34^{+}$cells, or is an unpurified suspension equally efficacious? Can similar results be achieved in patients who are placed on cardiopulmonary bypass, or does the resultant inflammatory response impair the engraftment of the trans- planted cells? Can injection into the central scar area truly regenerate infarcted myocardium, or is it necessary to inject cell isolates into potentially viable tissue? Most of these latter questions will be answered in future clinical trials by this ambitious group of investigators. I applaud them for their scientific rigor in applying a prospective randomized approach to the evaluation of this exciting new therapy.

\section{References}

1. Quaini F, Urbanek K, Beltrami AP, et al. Chimerism of the transplanted heart. $N$ Engl J Med. 2002;346:5-15.

2. Orlic D, Kajstura J, Chimenti S, et al. Bone marrow cells regenerate infracted myocardium. Nature. 2001;410:701-5.

3. Menasche P, Hagege AA, Scorsin M, et al. Myoblast transplantation for heart failure. Lancet. 2001;357:279-80.

4. Al Radi OO, Rao V, Li RK, Yau TM, Weisel RD. Cell transplantation-closer to bedside. Ann Thorac Surg. 2003;75(suppl):S674-7.

5. Patel AN, Geffner L, Vina RF, et al. Surgical treatment for congestive heart failure using autologous adult stem cell transplantation: a prospective, randomized study. J Thorac Cardiovasc Surg. 2005;130:1631-8.

6. Chu V, Giaid A, Kuang JQ, et al. Thoracic Surgery Director's Award. Angiogenesis in transmyocardial revascularization: comparison of laser versus mechanical punctures. Ann Thorac Surg. 1999;68:301-7. 